\title{
The Adult Arithmetic History Questionnaire
}

Dana Sury ${ }^{1,2}$, Nadine Gaab ${ }^{1,2,3}$

${ }^{1}$ Laboratories of Cognitive Neuroscience, Division of Developmental Medicine, Department of Medicine, Boston Children's Hospital, Boston, Massachusetts, U.S.

${ }^{2}$ Harvard Medical School, Boston, Massachusetts, U.S.

${ }^{3}$ Harvard Graduate School of Education

\section{Correspondence}

Nadine Gaab, PhD

Laboratories of Cognitive Neuroscience

Department of Medicine/Division of Developmental Medicine

Boston Children's Hospital

\section{Autumn Street}

Boston, MA 02215

Nadine.gaab@childrens.harvard.edu 


\section{Introduction}

The Adult Arithmetic History Questionnaire (AAHQ) is a self-report survey tool designed to measure the history of arithmetical difficulties in adults. The AAHQ was developed based on the Adult Reading History Questionnaire (ARHQ, Lefly \& Pennington, 2000) to allow a comparison between an individual's history of reading and arithmetic development (including potential difficulties) across the lifespan. Using a self-report survey, the AAHQ aims to assess the history and persistence of difficulties in learning arithmetic and the overall use of arithmetic across the lifespan. It focuses on early number knowledge, on potential difficulties in learning basic arithmetic and arithmetical facts retrieval, and the daily use of numbers and arithmetic from childhood to adulthood.

The AAHQ has yet to be validated, and normative scores are unavailable at this point. We here introduce this version of the $\mathrm{AAHQ}$ and invite researchers to use it and to comment on the questionnaire. We further encourage the research community to share norming data with us. Once available, these will be combined and shared with the research community.

\section{References:}

Lefly, D. L., \& Pennington, B. F. (2000). Reliability and validity of the adult reading history questionnaire. Journal of Learning Disabilities, 33(3), 286-296. 


\section{Adult Arithmetic History Questionnaire}

Please complete the survey below.

Thank you!

1) Parent Identification
○ Biological Mother
O Biological Father
○ Non-Biological Caregiver

2) Which of the following most nearly describes your attitude toward arithmetic when you were a child?
00 Very positive
○ 1
○ 2
$\circ 3$
○ 4 Very negative
3) How much difficulty did you have learning math facts (addition,
○ 0 None subtraction, multiplication, division) in elementary school?
○ 1
$\circ 2$
○ 3
$\circ 4$ A great deal

4) How much extra help did you need when learning math in elementary

○ 0 No help school?

○ 1 Help from friends

○ 2 Help from teachers/ parents

○ 3 Tutors or special class 1 year

○ 4 Tutors or special class $2+$ years

5) Did you have difficulty learning number names and counting when you were a child?
$\circ 0$ No
$\circ 1$
$\circ 2$
$\circ 3$
$\circ 4$ A great deal

6) Did you have difficulty recognizing printed numbers when you were a child?
O 0 No
$\circ 1$
$\circ 2$
$\circ 3$
$\circ 4$ A great deal

7) Did you have poor memory for numbers when you were a child?
O 0 No
○ 1
$\circ 2$
○ 3
$\circ 4$ A great deal

8) Did you ever reverse the order of numbers or counted incorrectly
O 0 No
$\circ 1$
$\circ 2$
$\circ 3$
$\circ 4$ A great deal

when you were a child?

9) How would you compare your math skill to that of others in your elementary classes?

O 0 Above average

O 1

○ 2 Average

O 3

○ 4 Below average 
10) Did you have difficulty developing math problem-solving skills in elementary school?
O 0 No
○ 1
○ 2
○ 3
○ A great deal

11) All students struggle with math from time to time in school. In
O 0 Not at all
O 1 Less than most
O 2 About the same
O 3 More than most
O 4 Much more than most comparison to others in your classes. How much did you struggle to complete your math work?

12) Do you experience difficulty in estimating costs such as groceries bills?
O 0 No
○ 1
$\circ 2$
O 3
$\circ 4$ A great deal

13) What is your current attitude toward arithmetic?

O 0 Very positive

$\circ 1$

○ 2

○ 3

○ 4 Very negative

14) Do you use mental arithmetic to cope with every-day calculations or do you prefer to use a calculator (e.g., during shopping or paying bills)?

O 0 Mostly use mental math

○ 1

○ 2 Use mental math and calculators equally

○ 3

○ 4 Mostly use calculators

15) How would you compare your current arithmetical skills to that of others of the same age and education?
O 0 Above average
$\circ 1$
○ 2 Average
O 3
○ 4 Below average

16) Do you struggle with understanding concepts and estimating time and/or distance?
O 0 No
○ 1
○ 2
$\circ 3$
$\circ 4$ A great deal

17) How much difficulty did you have learning the multiplication table in elementary school?
O 0 None
O 1
○ 2 Some
O 3
$\circ 4$ A great deal

18) Do you have difficulty remembering addresses, phone numbers, or dates?

O 0 None

O 1

○ 2 Some

○ 3

$\circ 4$ A great deal 
19) Do you have trouble remembering numbers or instruction that involve numbers and simple calculation (e.g., prices, percentage, medication

O 0 No

○ 1

dosage)?
○ 2

○ 3

○ A great deal
20) Do you currently reverse the order of numbers when you read or write numbers, or do math?
O 0 No
○ 1
○ 2
○ 3
○ A great deal

21) Did you avoid using mathematics during your education?

O 0 No

○ 1

○ 2

○ 3

○ A great deal

22) Would you prefer to write an essay than to do an assignment in math?

0 Prefer to do math

○ 1

○ 2 No preference

○ 3

○ 4 Prefer to write an essay
23) How much do you use numbers to describe measures such as distance or weight?
O 0 Every day
o 1 Once a week
O 2 Once in a while
○ 3 Rarely
○ 4 Never

\begin{tabular}{|c|c|c|}
\hline 25) & $\begin{array}{l}\text { Do you struggle with understanding basic arithmetical concepts such } \\
\text { as the base-10 system and calculating with decimals and fractions? }\end{array}$ & $\begin{array}{ll}\circ & 0 \text { No } \\
\circ & 1 \\
\circ & 2 \\
\circ & 3 \\
\circ & 4 \text { A great deal }\end{array}$ \\
\hline 26) & $\begin{array}{l}\text { Do you like doing games that involve numbers (e.g., such as soduko or } \\
\text { monopoly) in your free time? }\end{array}$ & $\begin{array}{l}\text { O } 0 \text { Every day } \\
\text { O } 1 \text { Once a week } \\
02 \text { Once in a while } \\
\text { O } 3 \text { Rarely } \\
04 \text { Never }\end{array}$ \\
\hline
\end{tabular}

27) Anything else you'd like to share? 